\title{
Exploring the Moderating Effects of Socio-Demographic Variables on Consumer Acceptance and Use of Mobile Money Transfer Services (MMTs) in Southern Zimbabwe
}

\author{
John Marumbwa
}

Department of Management Studies, Great Zimbabwe University, Masvingo, Zimbabwe.

Email: jmarumbwa@gmail.com

Received November 25 ${ }^{\text {th }}$, 2013; revised December 25 $5^{\text {th }}$ 2013; accepted December $30^{\text {th }}, 2013$

Copyright (C) 2014 John Marumbwa. This is an open access article distributed under the Creative Commons Attribution License, which permits unrestricted use, distribution, and reproduction in any medium, provided the original work is properly cited. In accordance of the Creative Commons Attribution License all Copyrights (C) 2014 are reserved for SCIRP and the owner of the intellectual property John Marumbwa. All Copyright (C 2014 are guarded by law and by SCIRP as a guardian.

\begin{abstract}
The changing competitive landscape for mobile telecom service companies in Zimbabwe has significantly contributed to the launch of innovative market offerings, in particular, the mobile money transfer services (MMTs). The high uptake of mobile phone technology has triggered intense competition amongst the three major players: Econet, Telecel and Netone along with traditional banking and financial institutions. The purpose of the study was to explore the moderating effects of socio-demographic variables: age, gender, income, education and employment status on frequency of use (FOU), use of MMT applications and the actual user acceptance of MMT services. The survey results were obtained from a sample of $\mathbf{3 5 0}$ respondents. A semi-structured interview guide was used to gather primary data on FOU, use of MMT applications and acceptance of MMT services in Southern Zimbabwe. Data on consumer socio-demographic profiles were recorded during the interviews. The major findings were that age, gender and income negatively affect MMT user acceptance whilst education levels and employment status are key socio-demographic variables that predict FOU, use of MMT applications and actual user acceptance of MMTs.
\end{abstract}

\section{KEYWORDS}

Mobile Money; Mobile Penetration; Money Transfer Services; Socio-Demographics; User Acceptance

\section{Introduction}

The burgeoning technological innovations have stimulated unparalleled metamorphosis of the business facade across the globe. The world-wide expansion of the mobile telecommunications services sector has brought about new possibilities, transforming the financial services sector in particular. In Zimbabwe, the mobile telecommunications market has realized vast growth over the last five years. Prior to the introduction of the multi-currency financial systems in early 2009, infrastructural development, manufacturing sector, financial services sector and even the once flourishing agriculture sector witness retarded growth for a decade. Notwithstanding this, the admittance and definite use of mobile phones have dramatically increased just as has been the trend in other sub-Saharan countries. In general, for both the rural and urban population, the effects of these developments among other things have improved basic communication, and reduced communication costs, convenience in transmitting information due to the mobility and ubiquity nature of mobile phones.

The emerging literature and scholarly research on mobile phones have focused on antecedents of mobile phone use and acceptance [1], predicting the factors influencing consumer purchase behavior of mobile phones [2], determinant factors of consumer choice of mobile phones [3-7], factors affecting the demand of Smartphone among young adult [8], validating antecedents of customer loyalty for Indian cell phone users [9], and also understanding student attitude of mobile phone applications and tools [5]. Whilst Zimbabwe, like other developing coun- 
tries, has lagged behind in adopting mobile telecom technology, the growth in mobile phone use and rapid market acceptance have generated a great deal of conjecture and sanguinity amongst the media, businesses, multinational companies, governments, economic agents, consumers and society at large. The great optimism has emanated from two paradigms: reaching the unbanked rural population with easy, fast and convenient financial service delivery platforms and leveraging mobile phone technology to enhance socio-economic development through such applications as mobile commerce (mcommerce).

A growing trend in Africa suggests that the mobile telecommunications markets are slowly reaching the saturation phase, and mobile phones are evolving from basic communication tools into a commercial medium particularly a financial service delivery platform [10]. A mere personal gadget has turned into a commercial tool and this presents an interesting paradox. Furthermore, competition in the mobile telecoms industry the world over is stiffening by the day and Zimbabwe is no exception. Conventional product and brand management literature posits that as products or brands become similar, the focus of competition swing from the core/basic product to the augmented product level thus, rivalry has forthwith shifted from basic communication and tariff charges to $3 \mathrm{G}$ services and wireless broadband networks. In addition, mobile telecoms companies have further diversified their services resulting in the launch of a plethora of financial service products. New innovative mobile telecom application services include mobile banking, mobile payments, mobile commerce and mobile money transfer services [11-13].

Despite the fact that the broader scope of mobile commerce- the acceptance and use of services such as mobile banking and mobile payments, have received significant attention of many scholars in recent times [1018], literature and empirical studies on mobile money are still a limited few. Interestingly, available literature is pivoted on analysing antecedents of consumer adoption of mobile payments, particularly extension of the renowned Technology Acceptance Model (TAM) with no concentrated studies documented on understanding the moderating effects of socio-demographic variables on consumer acceptance and use of mobile money transfer services. Consumer behaviour literature alludes to the notion that the consumer socio-demographic factors tend to moderate the consumer purchase behaviour for industrial and consumer goods [19]. This is chiefly because they largely form part of an individual's inherent buying culture and usually dictates the type of products purchased, the spending pattern and overall purchase behaviour.

\section{Mobile Money}

[10] posits that since 2005, mobile financial applications (known as "m-money" or "m-banking") have emerged in various developing economies. In general, mobile money transfer systems can be described as a set of applications that facilitate a variety of financial transactions via mobile phone, including transmitting airtime, paying bills, and transferring money between individuals. [13] defines mobile money transfer services as the process of transmitting money from one person to another through phone activation that can be ultimately honoured with cash transactions by a financial or business institution. Put simply, mobile money refers to money that can be accessed and used via mobile phone or any wireless or computer device such as personal data assistants (PDAs) [18].

It is essential to note that most of the prior definitions describe mobile money comparatively to 'paper' money. Technically, mobile money platforms basically involve electronic or digital transactions conducted using a mobile terminal and a wireless network [20]. In this case, mobile terminals include all portable devices such as mobile handsets, mobile hand-held devices such as feature phones, smart phones and pocket PCs which are compatible to transfer money across subscribers. Resultantly, this paper defines mobile money transfer systems as digital or electronic mechanisms by which individuals or groups of people conduct monetary digital and electronic transactions via telecommunications terminals. Most m-money systems are designed to facilitate mobile subscribers to store value in an account accessible by the mobile handset, convert it into cash in and out of the stored value account, and transfer value between users by using a set of text messages, menu commands, and personal identification numbers $[10,13]$. Typically, one user can send e-money to another recipient with a phone, who then bank or send e-money to another recipient with a phone, who then withdraws the e-money from their local transfer agent with transactional fees levied for each transaction [13].

\subsection{Mobile Money Transfer Platforms in Zimbabwe}

Zimbabwe is a landlocked developing country in SubSaharan Africa with a population of over 12 million people. The economic landscape is on a resurgence after undergoing a meltdown in the past decade that has had a momentous crash on the lives of its citizens. Latest figures on the Human Development Index (HDI) indicate that Zimbabwe ranks 173 out of 187, [21]. In addition, the market is characterised by high unemployment rates despite the exceptionally high literacy levels, multi-currency financial system, relatively stable political climate, 
growing middle aged population, booming mining and agriculture sectors, ricochet tourism industry. Historically, the Zimbabwean economy was iconic specially compared to other Southern African economies with improved infrastructure enabling sufficient mobile network coverage and networking to almost all corners of the country. The expose of the demographic landscape in Zimbabwe indicate sufficient market for mobile telecom companies and subsequent launch of innovative products to meet growing demand. A growing young and middle aged population is deemed a potential market for mobile telecom services and related innovations such as mobile money despite the macro-economic destabilisation and the bank crisis of 2003-2008 which crippled market capitalisation and eroded depositor and investor confidence in the financial service industry.

The Zimbabwean mobile telecom market is dominated by three major players: Econet, Telecel and Netone. Historically, the introduction of mobile telecoms services in Zimbabwe started in the mid to late 1990s [22]. The first mobile telecoms services brand to be launched in Zimbabwe is Netone, a private limited company wholly owned by the government which commenced operation with 500 lines in September 1996 during the World Solar Summit in Harare [23]. Econet Wireless Zimbabwe which became the second service provider was incorporated in 1994 and launched its network on the $10^{\text {th }}$ of July, 1998. Presently, the company is one of the largest corporations (listed on the Zimbabwe Stock Exchange) by market capitalisation and the largest provider of telecommunications services, mobile and fixed wireless telephone, public payphones, internet access and payment solutions [24]. Telecel Zimbabwe Limited which claims to be the second largest mobile telecoms services network in Zimbabwe, with more than 2.5 million active subscribers was the last to be launched. The firm is jointly owned by Telecel Globe and Empowerment Corporation wherein the former is a subsidiary of Orascom Telecom Company, a major international telecommunications company with interests in Europe, Africa, Asia, the Middle East and North America and the latter a consortium made up of a number of Zimbabwean companies [25].

It suffices to mention that competition amongst the three players has intensified evidenced by continuous and heavy jostling for subscribers, promotional pricing meant to stimulate brand switching, aggressive customer acqui- sition and retention strategies, customer loyalty programs, continuous product innovation and modification meant to lock in the subscribers. Notwithstanding, the most recent statistics on mobile penetration in Zimbabwe depict a sharp increase in the uptake and use of mobile phone technology [26]. Table 1 shows the mobile penetration growth rate for the dollarization period (2008 to 2012). In their report on Mapping the Retail Payment Service Landscape, Zimbabwe, [21] propound that mobile phone technology provides the potential to expand financial services well beyond the existing financial sector distribution networks. They add that Zimbabwe has experienced exponential growth in mobile subscriptions, particularly in the post multi-currency period when the stabilization of the economy coincided with growth in mobile penetration across the African continent.

Although the introduction of mobile money platforms originated from the conventional bank financial systems, the development of mobile money platforms by MNOs in Zimbabwe began in the course of the year 2011. Econet Wireless Zimbabwe rolled out its own version branded EcoCash, and later on Netone and Telecel introducing OneWallet and Skhwama respectively. Several banks could not weather the storm and followed suit. Table 2 shows the major mobile money platforms in Zimbabwe. It is interesting to note that most if not all of the mobile money platforms in Zimbabwe are primarily a hub on familial transfer of funds and essential payment services such as bill payment and airtime-top-up, mainly among existing clients [21].

Market watchers, industrialists, media houses and business analysts agree that the most dominant and widely used mobile money platform by both the banked and unbanked Zimbabweans is EcoCash, riding particularly on its parent company (Econet)'s high subscriber base estimated to be above 6million subscribers coupled with the expansive marketing efforts. According to the recent GSM Association survey report [26] and a local weekly business paper, Fingaz, EcoCash has to date managed to register (though not all registered customers are active customers) 3 million subscribers, established

Table 1. Mobile penetration rates 2008-2012.

\begin{tabular}{llllll}
\hline Year & 2008 & 2009 & 2010 & 2011 & $* 2012$ \\
\hline Mobile Penetration Rate & $17 \%$ & $41 \%$ & $62 \%$ & $72 \%$ & $* 97 \%$ \\
\hline Source: [21,26]. & & & & &
\end{tabular}

Table 2. Mobile money platforms in Zimbabwe.

\begin{tabular}{cccccc}
\hline Service Provider & Econet & CABS & Tetrad & Netone & Kingdom \\
\hline M-money Platform & EcoCash & Textacash & eMali & OneWallet & CellCard \\
\hline
\end{tabular}

Source: [21]. 
4000 agents, conduct \$200 million transactions per month among other achievements within its first two years of operation. In a bid to improve on operations, EcoCash management announced a new mobile money service product branded EcoCash Save which is considered a "new savings account" transforming the service into a one stop financial service house. Not surprisingly, the domain of this study was pinned on effects of demographics on acceptance and use of primarily EcoCash services in Southern Zimbabwe although other mobile money platforms were considered as well.

\section{Moderating Effects of Socio-Demographic Variables}

Despite huge contributions on the body of literature on mobile money in recent years, there is inadequate scholarly research on consumer demographics and use and acceptance of MMTs. Prior studies have majored on investigating the antecedents of consumer adoption or preliminary studies [13,14,27,28]. Moreover, related studies are so recent $[19,29]$ and have attempted to elaborate on the effects of consumer demographics on use and acceptance of IT. [30] expounded on the moderating effects of age, gender and experience when they modeled the Unified Theory of Acceptance and Use of Technology (UTAUT2). Figure 1 depicts the UTAUT2 model which incorporates the moderating effects of age, gender and user experience. Their major conclusions were that: the impact of habit on IT use behavior differs with age, gender, and experience, specifically, older men with ex- tensive experience, tend to be driven by habit; older women in the early stages of using a particular technology, rely more on external resources to facilitate their continued use of the technology; younger men are motivated more by the hedonic benefits gained from using a technology and finally, older women, emphasize price value of the technology which inevitably suggest that older women are more price sensitive than other cohorts of consumers.

In a similar study on the Influence of Demographic factors on Adoption Level of Mobile Banking Applications in Jordan by [19] demographic factors were found to be the most important variables that affect the use and adoption of any new technology. In essence, they investigated the impact of four socio-demographic variables: age, gender, education and income levels and discovered that the level of education was the strongest positive factor whilst income levels negatively affect consumer adoption of mobile banking applications in Jordan, and also uptake was high amongst younger male generation. It is also interesting to note that very few studies have been conducted in Zimbabwe not to even mention Africa as a whole. As such it is imperative to explore and investigate the phenomenon, the subjects and constructs given the unique socio-demographic profiles of the Zimbabwean economy notwithstanding the differences in banking cultures between Arab economies and sub-Saharan African economies. In particular, this research study investigates the influence of Zimbabwe's high literacy levels, low income levels, (wherein more than half of the

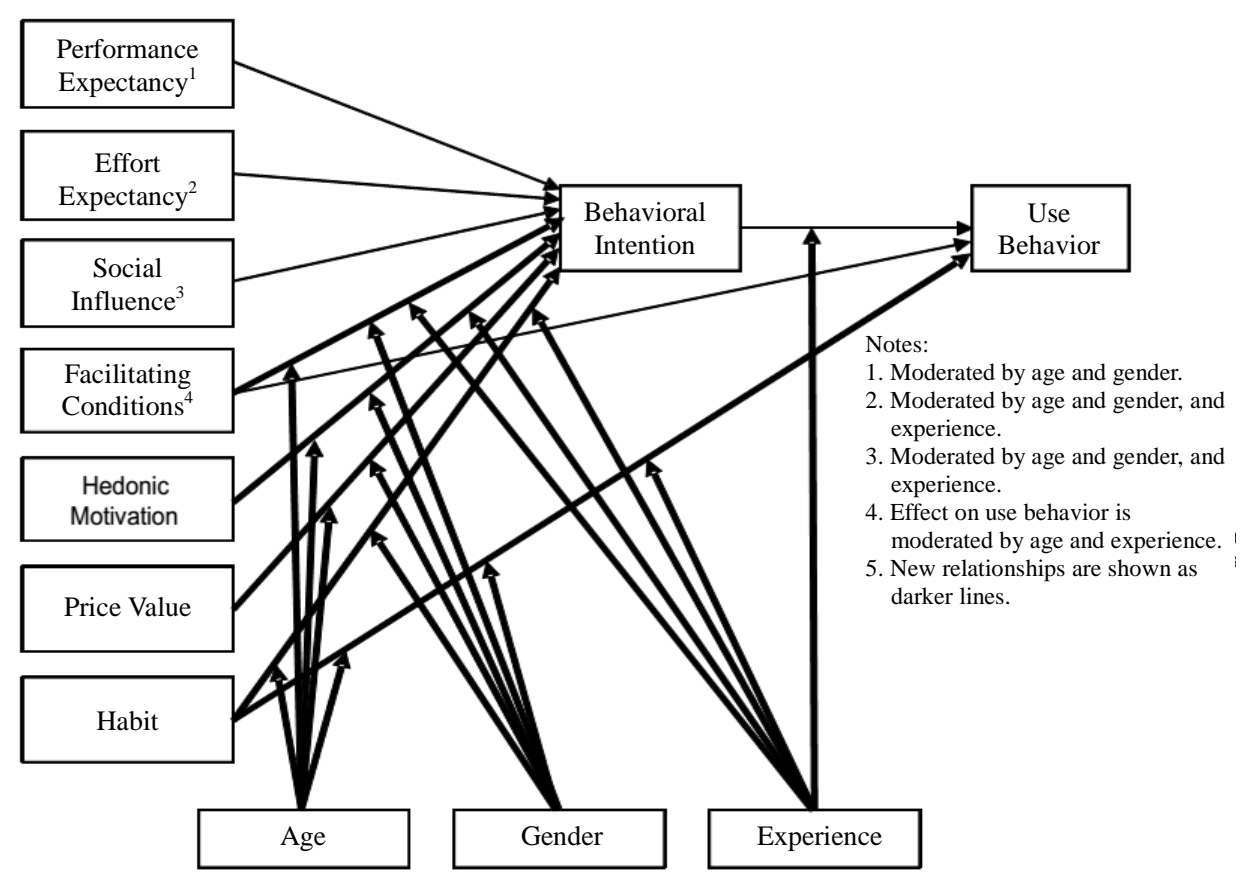

Figure 1. UTAUT2 Model. 
population earns below the poverty datum line, PDL), gender, and employment status on the background of a highly expanding informal sector driven by the government's indigenisation and empowerment policy.

Although projections by the ITU World Telecommunication in 2013 indicate that there will be almost as many mobile-cellular subscriptions as people in the world, with more than half in the Asia-Pacific region (3.5 billion out of 6.8 billion total subscriptions), there is need to explore the effects of socio-demographics on acceptance and use of mobile money transfer services in Zimbabwe. Several questions which require empirical solutions include:

- What are the moderating effects of different consumer age-groups on acceptance and use of MMTs in Zimbabwe?

- How do gender, income, education, and employment status moderate the actual acceptance and usage of MMTs in Zimbabwe?

- How do consumer socio-demographic variables influence frequency of usage, use of particular MMT service applications and ultimate acceptance of MMTs in Zimbabwe?

Resultantly, a conceptual model framework (depicted in Figure 2) was developed illustrating the possible correlations if any, between socio-demographic variables and acceptance and use of MMTs.

\section{Hypotheses Statements}

$H_{1}$ : The frequency of use of mobile money transfer ser- vices varies with varying consumer socio-demographic variables: age, gender, income, education, employment status,

$\mathrm{H}_{2}$ : The use of specific mobile money transfer service applications is largely dependent on consumer sociodemographic variables: age, gender, income, education, employment status,

$\mathrm{H}_{3}$ : The consumer acceptance of mobile money transfer services is influenced by socio-demographic variables: age, gender, income, education, employment status.

\section{Data Collection Procedures}

The primary goal of this study is to explore the moderating effects of socio-demographic variables on acceptance and use of MMTs in Zimbabwe. Primary data collection was done using a semi structured interview guide. The interview questions were developed through a review of literature on MMTs use, acceptance and adoption, whilst information on consumer demographics was obtained and recorded during the face-to-face interaction between researcher and respondents. The interview guide comprised of unique sections: Section A, focused primarily on the most used mobile money platform and the frequency of use per month; Section B solicited data on MMT service applications used, that is, money transfer (send or receive), bill payment, airtime top-up; Section C sought data on user acceptance of MMTs, that is customer willingness to continue using MMTs, satisfaction levels with MMTs, and commitment to MMT usage. Finally, data on consumer demographics, that is, age,

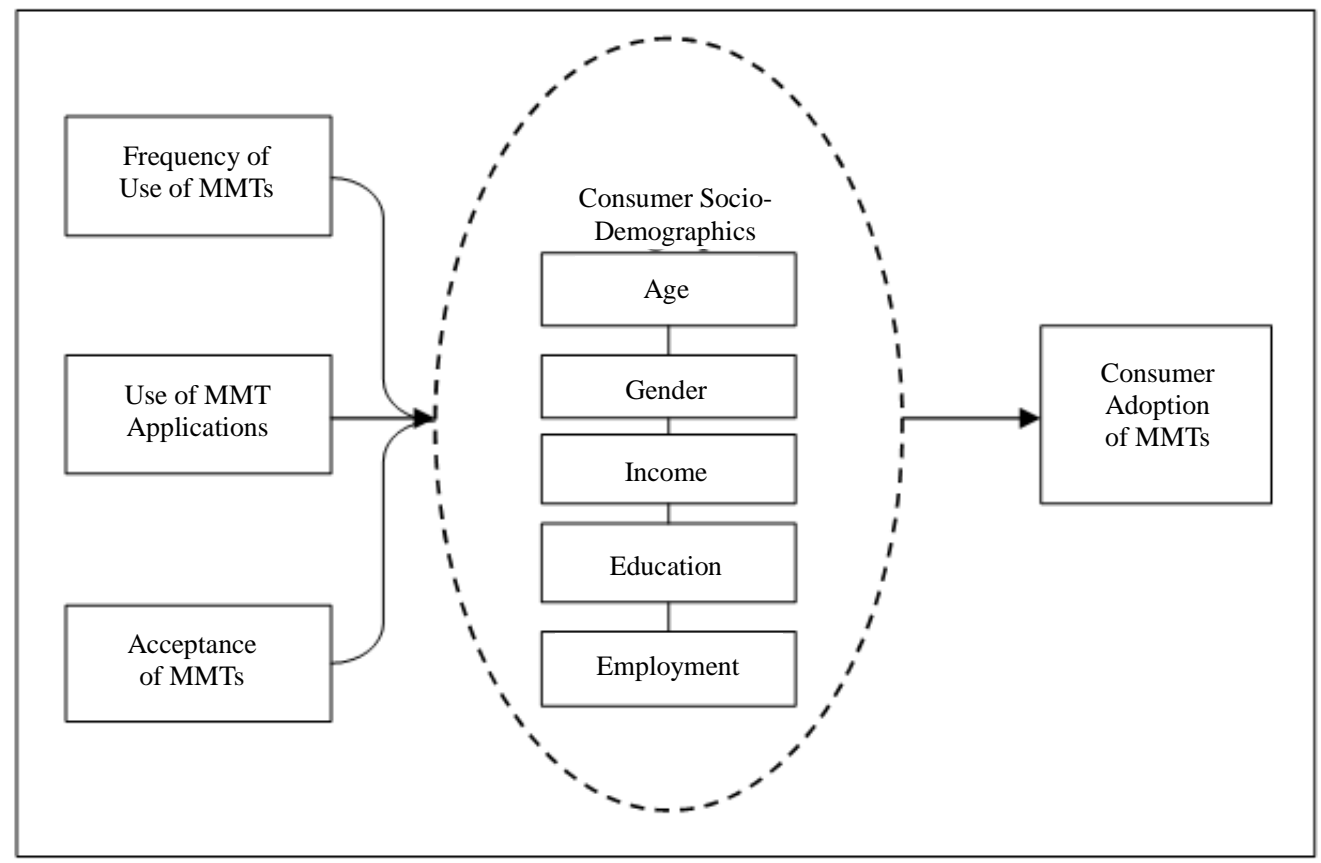

Figure 2. Conceptual model: Socio-demographic variables and acceptance \& Use of MMTs. 
gender, income level, education level, and employment status were collected and recorded during the face-toface interviews. A survey method was adopted which allowed access to diverse views and propositions especially with regards to the time and space constraints.

Non-probability sampling techniques (convenient and purposive) were used whereby questionnaires were methodically distributed at public and private entities, shopping malls, market places, tertiary educational institutions and major pedestrian pathways in Masvingo, Triangle and Chiredzi town. The technique was chosen considering that the subject (mobile money) is a mass market product which appeals to all individuals and the same were thus qualified prospective study participants. Study questionnaires were administered through face-to-face interactions between research assistants and respondents. In total, 500 questionnaires were distributed as follows; Masvingo-250 (182 valid); Chiredzi-150 (106 valid) and Triangle-100 (62 valid) and only 350 respondents were considered valid and qualified for data analysis giving a success rate of $70 \%$ which is good in light of the time, cost and geographic dispersion constraints. The data was collected at the end of August and September 2013 during which the selected towns would experience a hive of activity. A filter question was used to qualify the registered and active MMTs subscribers. The SPSS statistical package was used for data analysis, computation of the descriptive statistics; and correlation analysis to test the hypotheses statements.

\section{Findings and Discussions}

The descriptive statistics and correlation coefficient analysis were used to summarise the survey results and test the hypotheses statements proposed. Table 3 shows the descriptive statistics of the survey results.

\subsection{Age and Gender}

A total of 170 (48.5\%) study participants were aged between 16 years to 24 years, and 155 (42.2\%) fell into the 25 - 40 year age group. The remaining 25 (7.3\%) were aged above 41 years. It can therefore be clearly construed

Table 3. Descriptive statistics: Socio-demographics.

\begin{tabular}{|c|c|c|c|c|c|}
\hline Variable & Frequency & Percent & Variable & Frequency & Percent \\
\hline Age (years) & & & Education & & \\
\hline $16-24$ & 170 & 48.5 & Secondary & 67 & 19.2 \\
\hline $25-40$ & 155 & 44.2 & Certificate/Diploma & 123 & 35.1 \\
\hline $41+$ & 25 & 7.3 & Bachelor's Degree & 116 & 33.1 \\
\hline \multirow[t]{2}{*}{ Total } & 350 & 100 & Postgraduate & 44 & 12.6 \\
\hline & & & Total & 350 & 100 \\
\hline Gender & & & Employment Status & & \\
\hline Male & 184 & 52.6 & Formally employed & 134 & 38.3 \\
\hline Female & 166 & 47.4 & Self-employed & 41 & 11.7 \\
\hline \multirow[t]{2}{*}{ Total } & 350 & 100 & Student & 140 & 40 \\
\hline & & & Unemployed & 35 & 10 \\
\hline Income (USD) & & & Total & 350 & 100 \\
\hline$<100$ & 34 & 9.7 & & & \\
\hline $100-500$ & 207 & 59.2 & & & \\
\hline $501-1000$ & 83 & 23.7 & & & \\
\hline $1000+$ & 26 & 7.4 & & & \\
\hline Total & 350 & 100 & & & \\
\hline
\end{tabular}


and Use of Mobile Money Transfer Services (MMTs) in Southern Zimbabwe

that the bulk of the respondents (48.5\%) are young consumers who are generally tech savvy and as such may therefore readily embrace new innovative technology products such as MMTs. This observation confirms Davis (1989)'s proposition that young consumers are highly technologically active in terms of their adoption, understanding, usage and perception of new tech products and applications. In terms of gender, a total of 184 respondents (52.6\%) were males and 166 (47.4\%) were females. This trend could possibly be attributed to the fact that a significant number of the research assistants were predominantly males which presumably made it easy for them to approach their male counterparts. It is interesting to note that this profile somewhat contradicts the Zimbabwe national statistical findings whereby females occupy a greater percentage of the total population compared to males.

\subsection{Income Level}

Results on participants' levels of income show that a total of 34 (9.7\%) earned below \$100.00, with 207 respondents earning between $\$ 100.00$ and $\$ 500.00$ (59.2\%), while 83 (23.7) fall within the income range $\$ 501.00$ $\$ 1000.00$ and finally only 26 (7.4\%) fall within the \$1 000.00 and above wage range. The findings confirm the notion that most Zimbabweans earn below the Poverty Datum Line (PDL) currently pegged slightly above $\$ 500.00$. Despite this seemingly bleak picture, the income bands above reveal a greater potential amongst participants to access and eventually use MMT platforms which is reflective of the assertions made by Dermish et al (2012) that MMT service applications are equally suitable for and accessible to both low and high income earners mainly because they are characterised by low value transactions.

\subsection{Education Level and Employment Status}

The education level results indicate that $19.2 \%$ of the study participants had attained secondary education at the time this study was undertaken. A further $35.1 \%$ had certificates or diplomas, whilst another $33.1 \%$ had attained at least a Bachelor's degree with only 12.6 percent having reached the Postgraduate degree level. A striking remark can be made that no respondent fell into the primary level category and this observation therefore implies that there exists a relatively high literacy rate which may ultimately generate a huge appetite' for use and acceptance of tech-related products in Zimbabwe. In as far as the employment status is concerned, survey findings revealed that $38.3 \%$ of the respondents were formally employed, $11.7 \%$ were self-employed, and $40 \%$ were students with the unemployed constituting only $10 \%$. It is therefore observable that most of the study participants were students and formally employed customers who have a greater propensity to consume new technology services and applications [13,14,19].

\subsection{Pearson Correlation Analysis}

Further analysis was done to predict the moderating effects of socio-demographic variables on acceptance and use of MMTs whereupon results are depicted in Table 4. In light of the main objective of the study: to investigate the moderating effects of consumer socio-demographic factors on frequency of use (FOU), use of specific MMT applications and the actual acceptance/adoption of MMTs, the Pearson correlation coefficients were computed (considered significant at $\mathrm{p}<0.05$ ) to ascertain the nature of the relationship between the aforementioned dependant and independent variables.

With respect to the FOU of MMTs, age $(r=0.066$ and $p=0.219)$, gender $(r=0.51$ and $p=0.343)$ have weak insignificant relationship with FOU whilst income $(\mathrm{r}=$ 0.12 and $p=0.024$ ) have a weak but significant relationship. On the other hand, it is worth noting that FOU is positively related to education level $(r=0.59 ; \mathrm{p}=0.000)$ and employment status $(r=0.679$ and $\mathrm{p}=0.000)$. This indicate that whilst the level of education and the employment status contribute significantly to FOU, other socio-demographic variables such as age, gender and income levels do not really matter. The implication is that the FOU of MMTs does not vary with varying sociodemographic variables such as age, gender and income levels.

The Pearson coefficient results for use of MMT appli-

Table 4. Pearson correlation results.

\begin{tabular}{ccccccc}
\hline Variables & \multicolumn{2}{c}{ Frequency of Use } & \multicolumn{2}{c}{ Use of MMT Applications } & \multicolumn{2}{c}{ Acceptance of MMTs } \\
\hline & r-value & p-value & r-value & p-value & r-value & p-value \\
Age & 0.066 & 0.219 & -0.109 & 0.044 & 0.93 & 0.05 \\
Gender & 0.051 & 0.343 & -0.168 & 0.002 & -0.304 & 0.000 \\
Income & 0.12 & 0.024 & -0.123 & 0.023 & -324 & 0.000 \\
Education & 0.59 & 0.000 & 0.648 & 0.01 & 0.308 & 0.477 \\
\hline
\end{tabular}


cations show that their use varies with varying sociodemographic variables. Interestingly, there are negative correlations between use of MMT applications and the following socio-demographic variables: age $(-0.109)$; gender $(-0.168)$ and level of income $(-0.123)$. The implication is that the use of MMT applications is high amongst the young consumers and significantly low amongst their elderly counterparts. The outcome can be attributed to the fact that MMTs usually involve low value transactions which are a characteristic feature of young consumers particularly students who receive monthly stipends from their parents or guardians for general upkeep at university or college. However, with respect to education levels and employment status, there is a positive linear relationship (0.648 and 0.936 respectively) with the only notable distinction of their significance values. Education level is considered insignificant (0.01) whilst employment status is regarded as significant (0.004). Resultantly, it can be argued that employment status is a contributing predictor to the use of MMT applications therefore MMT providers should target different work categories and set-ups with unique MMT applications.

The third statement of hypothesis sought to predict the influence of socio-demographic factors on the actual user acceptance of MMTs. Again the Pearson correlation analyses were used to test the existence and nature of the relationship. Results indicate that actual acceptance of MMTs is largely influenced by the consumer age group $(r=0.93 ; p=0.05)$ and negatively related to gender $(r=$ $-0.304 ; p=0.000)$ and the level of consumer income $(r=$ $-0.324 ; \mathrm{p}=0.000$ ). However, it is prudent to mention that the significant relationship is somewhat weak which suggest that user acceptance of MMTs is independently related to gender and level of income. Notwithstanding, there is an insignificant relationship between level of education $(r=0.308 ; p=0.477)$ and user acceptance of MMTs which entails that the MMTs are financial products meant for the mass market regardless of their level of education. On the other hand, the Pearson correlation analysis results indicate a moderate positive relationship between employment status $(r=0.482 ; p=0.006)$ and user acceptance of MMTs which somehow indicate that MMT services like related conventional banking and financial services are targeted for the mass market. This therefore implies that MMT service providers should tailor make their offerings and promote extensively to the general populace rather than restrict them to certain markets or customer groups.

\section{Conclusion}

Several conclusions can be drawn up from the survey results. The findings revealed that the frequency of use of MMT is largely influenced by level of education and employment status whilst age, gender and level of income have insignificant influence. In the same vein, the use of specific MMT applications does not significantly vary with varying socio-demographic variables with the exception of employment status. Finally, age, gender and income levels are negatively correlated to the actual user acceptance of MMTs. In essence, the level of education and employment status are highly influential sociodemographic determinants of user acceptance of MMTs. In general, it is worthwhile to note that MMT services are not in any way different from conventional banking services but rather an extension thereof, wherewith MMT providers should tailor market offerings to meet the different customer segments. Despite the worthwhile findings and revelations, it is imperative to mention that the study was conducted in urban and semi-urban areas which therefore necessitate the need to conduct future research studies to establish the acceptance of MMTs in rural mobile telecoms markets.

\section{REFERENCES}

[1] Y. W. Lee, "Differences in Mobile Communication Technology Assessing the Factors Affecting Cellular Mobile Telephone Diffusion at the Country Level," University of Florida, Gainesville, 2005.

[2] J. Singh and B. B. Goyal, "Mobile Handset Buying Behaviour of Different Age and Gender Groups," International Journal of Business Management, Vol. 4, No.5, 2009, p. 180.

[3] H. Karjaluoto, et al., "Factors Affecting Consumer Choice of Mobile Phones: Two Studies from Finland," Journal of Euromarketing, Vol.14, No. 3, 2005,

[4] A. Singh, "Dream Bloggers,” 2012. http://www.dreambloggers.com/comparison-apple-iphone -5-vs-samsung-galaxy-s-ii-plusupcoming-phones/

[5] M. M. Head and N. Ziolkowski, "Understanding Student Attitudes of Mobile Phone Applications And Tools: A Study Using Conjoint, Cluster And SEM Analyses,” 18th European Conference on Information Systems South Africa, Pretoria, 7-9 June 2010, 12 p.

[6] M, Haverila, "Mobile Phone Feature Preferences, Customer Satisfaction and Repurchase Intent among Male Users,” Australasian Marketing Journal, Vol. 19, No. 4, 2011, pp. 238-246. http://dx.doi.org/10.1016/j.ausmj.2011.05.009

[7] R, Ebrahim, "A Structural Evaluation of the Determinants of Consumer of Consumer Brand Preferences for Mobile Phones in Egypt," Brunel Business School-Doctoral Symposium, London, 27-28 March 2012, pp. 1-11.

[8] M. M. Chow, et al., "Conceptual Paper: Factors Affecting the Demand of Smartphone among Young Adult," International Journal on Social Science Economics \& Art, Vol. 2, No. 2, 2012, pp. 332-334.

[9] H. Kaur and H. Soch, "Validating Antecedents of Cus- 
tomer Loyalty for Indian Cell Phone Users,” Vikalpa, Vol. 37, No. 4, 2012, pp. 47-61.

[10] J. C. Aker and I. M. Mbiti, "Mobile Phones and Economic Development in Africa," CGD Working Paper 211. Center for Global Development, Washington DC, 2010.

[11] N. Hughes, "M-PESA: "Mobile Money for the 'Unbanked' Turning Cell phones into 24-Hour Tellers in Kenya,” Innovations: Technology, Governance, Globalization, Vol. 2, No. 1-2, 2007, pp. 63-81.

[12] B. Jenkins, "Developing Mobile Money Ecosystems," IFC and the Harvard Kennedy School, Washington DC, 2008.

[13] P. Tobbin, "Modelling Consumer Adoption of Mobile Money Transfer Service: A Consumer Behaviour Analysis,” Aalbury, Denmark, 2008.

[14] R. Hoppe, et al., "Factors affecting the Adoption of Internet in South Africa: A comparative study,” University of Cape Town, Cape Town, 2001.

[15] D. Khodawandi, K. Pousttchi and D. G. Wiedemann, “Akzeptanz mobiler Bezahlverfahren in Deutschland,” In: K. Pousttchi and K.Turowski, Eds., Mobile CommerceAnwendungen und Perspektiven, Augsburg, 2003, pp. 4257.

[16] M. M. Udovicic, "Driving Consumer Acceptance of Mobile Marketing a Theoretical Framework and Empirical Study," Journal of Electronic Commerce Research, Vol. 6, 2006, pp. 181-192.

[17] S. K. Chitungo and S. Munongo, "Extending the Technology Acceptance Model to Mobile Banking Adoption in Rural Zimbabwe,” Journal of Business Administration and Education, Vol. 3, No. 1, 2013, pp. 57-79.

[18] J. Marumbwa and M. Mutsikiwa, "An Analysis of the Factors Influencing Consumers' Adoption of Mobile Money Transfer Services (MMTs) in Masvingo Urban Zimbabwe," British Journal of Economics, Management \& Trade, Vol. 3, No. 4, 2013, pp. 498-512.

[19] M. Alafeef, D. Singh and K. Ahmad, "Influence of
Demographic Factors on the Adoption Level of Mobile Banking Application in Jordan,” Journal of Applied Sciences, Vol. 6, No. 6, 2011, pp. 373-377.

[20] C. S. Veijalainen, "Personal Innovativeness, Social Influences and Adoption of Wireless Internet Services via Mobile Technology," Journal of Strategic Information Systems, Vol. 14, No. 3, 2003, pp. 245-268.

[21] A. Dermish et al., "Mapping the Retail Payment Services Landscape, Zimbabwe,” FinMark Trust, 2010

[22] J. Marumbwa, "A Pragmatic Assessment of the Determinants of Consumer Brand Preferences in the Mobile Telecommunications Services Market in Masvingo Urban, Zimbabwe," Management and Administrative Sciences Review, Vol. 2, No. 2, 2013, pp. 144-155.

[23] http://www.netone.co.zw/index.php?”History

[24] https://www.econet.co.zw/about-us/history

[25] http://www.telecel.co.zw/index.php/about-us/overview

[26] The EcoCash Mobile Payments Strategy and Number. A Case Study by GSMA, 2013. www.techzim.co.zw

[27] S. Chatziagapis, "Adoption of Mobile services in Greece," Anthens Information Technology, Athens, Masters Dissertation, 2006.

[28] N. Davidson and P. McCarthy, "Managing a Mobile Money Agent Network," A Handbook for Mobile Network Operators, 1998, pp. 54-67.

[29] D. and K. Ahmad, "The Influence of Demographic Factors and User Interface on Mobile Banking Adoption: A Review," Journal of Applied Sciences, Vol. 12, No. 20, 2012, pp. 2082-2095. http://dx.doi.org/10.3923/jas.2012.2082.2095

[30] V. Venkatesh, et al., "Consumer Acceptance and Use of Information Technology: Extending the Unified Theory of Acceptance and Use of Technology,” MIS Quarterly, Vol. 36, No. 1, 2012, pp. 157-178. 